\title{
WEEE flow and mitigating measures in China
}

\author{
Jianxin Yang ${ }^{\mathrm{a}, *}$, Bin $\mathrm{Lu}^{\mathrm{a}}$, Cheng $\mathrm{Xu}{ }^{\mathrm{b}}$ \\ ${ }^{a}$ Research Center for Eco-Environmental Sciences, Chinese Academy of Sciences, Shuangqing Road 18, Beijing 100085, China \\ ${ }^{\mathrm{b}}$ Chinese Research Academy of Environmental Sciences, Dayangfang 8, Beijing 100012, China
}

Accepted 24 August 2007

Available online 1 November 2007

\begin{abstract}
The research presented in this paper shows that Waste Electrical and Electronic Equipment (WEEE) issues associated with home appliances, such as TV sets, refrigerators, washing machines, air conditioners, and personal computers, are linked in the WEEE flow and recycling systems and are important to matters of public policy and regulation. In this paper, the sources and generation of WEEE in China are identified, and WEEE volumes are calculated. The results show that recycling capacity must increase if the rising quantity of domestic WEEE is to be handled properly. Simultaneously, suitable WEEE treatment will generate large volumes of secondary resources. Environmental problems caused by the existing recycling processes have been investigated in a case study. Problems mainly stem from open burning of plastic-metal parts and from precious metals leaching techniques that utilize acids.

The existing WEEE flow at the national level was investigated and described. It became obvious that a considerable amount of obsolete items are stored in homes and offices and have not yet entered the recycling system. The reuse of used appliances has become a high priority for WEEE collectors and dealers because reuse generates higher economic profits than simple material recovery. The results of a cost analysis of WEEE flow shows that management and collection costs significantly influence current WEEE management.

Heated discussions are ongoing in political and administrative bodies as to whether extended producer responsibilities policies are promoting WEEE recycling and management. This paper also discusses future challenges and strategies for WEEE management in China.
\end{abstract}

(c) 2007 Elsevier Ltd. All rights reserved.

\section{Introduction}

With rapid industrial expansion in China in the past several decades, especially in the IT industry, production and consumption of home appliances and personal electrical and electronic products have risen very quickly. At the same time, the lifespan of IT products is becoming shorter. As a result, the question of how to deal with Waste Electrical and Electronic Equipment, called WEEE for short, has become a controversially issue for both recycling industries and the government in China.

WEEE describes a wide range of products, from industrial equipment to household appliances (e.g., personal

\footnotetext{
* Corresponding author. Tel./fax: +86 1062849802

E-mail address: yangjx@rcees.ac.cn (J. Yang).
}

devices like mobile phones, computers, etc.), which have reached the end of their life. The definition and categories of WEEE vary in different countries.

Since the publication of the Basel Action Network (BAN) and Silicon Valley Toxicity (SVTC) report on WEEE exporting in 2002 (Basel Action Network, 2002), the Chinese government, academic institutions and the public have paid much attention to environmental problems resulting from WEEE recycling. Scientific studies and WEEE management programs mainly focus on environmentally friendly dismantling/disassembling and pollution control ( $\mathrm{Li}$ et al., 2004; Wang et al., 2006). In most cases, the incentives and dynamics that are created by material recovery from WEEE are neglected.

In the EU and USA, a number of studies on the production, use and recycling of WEEE using material flow assessment have estimated the future amount and composition of 
WEEE (CRAES, 2003). Several studies have also applied models that estimate future WEEE generation (Matthews et al., 1997; Matthews and Matthews, 2003). In addition, life cycle assessments and life cycle costing are used to evaluate the regulation of WEEE recycling (Huisman, 2003; Williams and Sasaki, 2003).

However, in China, a small amount of literature exists discussing the quantity of WEEE flow and its impact on markets (Liu and Yang, 2005; Lin and Wang, 2003). Consequently, up to now, there has been no clear definition in China of WEEE from either the official or academic arena. Basic data such as WEEE sources, generation, flow and recycling rates are also unavailable.

Since the European Council and Parliament released the EU directive on WEEE (EU, 2002), many European states have launched initiatives for the recycling of EEE. The directive has been in force since August 2004 and has continued to dictate national implementation since the August 2005 deadline for compliance. It obliges EU member states to install a recycling system for EEE with the objectives to: (i) reduce the quantity of WEEE that ends up in landfills; (ii) increase WEEE recovery, re-use and recycling; and (iii) mandate an extended producer responsibility for the whole EEE lifespan. While each country in Europe is currently working on enforcing a WEEE recycling system, much of the decision making is influenced by cost constraints.

As the objectives are quite complex, almost all EU countries have installed producer responsibility organizations (PRO). PROs are a cooperative industry effort to share the responsibility of WEEE recycling between members. Generally, the PROs are responsible for environmentally sound WEEE recycling and have the managerial authority to collect, distribute and transport WEEE, as well as to control and monitor recyclers.

Some non-EU countries, such as Switzerland and Norway, have also set up their own WEEE recycling systems and fully comply with the EU WEEE directive (StreicherPorte, 2005; Renningen, 2005).

However, China cannot fully duplicate the European WEEE system due to the characteristics of WEEE flow and recycling practices in China. Until now, WEEE recycling activities in China have been mostly performed informally in the industrial sector. WEEE in China is economically valuable, and its collection is a profitable business. As far as policies and regulations are concerned, China has no experience in how to manage WEEE recycling when compared with developed nations and will face severe challenges in addressing the pollution resulting from these activities if additional measures are not taken. In the past three years, several official pilot projects have been undertaken with the goal of establishing a formal recycling industry. The areas of success and failure from these projects should be reviewed. The current policy for formation framework and management system of WEEE in China is discussed in this paper.

\section{WEEE flow in China}

In contrast to the European Union or Japan, non-official and academic bodies have defined WEEE categories for China. The main categories of WEEE will not differ from those in other countries and include items such as home appliances, personal mobile devices, business electronics, and industrial equipment. The current policy focus is on home appliances and PCs, as determined by the National Development and Reform Commission (NDRC, 2004). There is no actual official data for WEEE generation and flow in China. In the following study, personal computers (PCs) and four appliances (televisions, refrigerators, washing machines, and air conditioners) from three WEEE categories are selected as examples of the whole range of EEE.

\subsection{The sources and generation of WEEE}

Chinese WEEE sources include both domestic generation and imports. WEEE imports are divided into legal and illegal imports. The former is managed and controlled by China Customs and State Environmental Protection Administration (SEPA). Domestic generation mainly comes from post-consumer e-products. Only small quantities come from industrial processes.

The calculation model is based on product sales data along with the products' medium life span. Since the 1980s, production and sale of home appliances and PCs have increased rapidly. Personal computer sales were 30,000 in 1990 and have increased to 9.60 million by 2003, an average annual increase of $55.8 \%$. By 2003, an estimated 420 million televisions were in use (Table 1). In other words, increasing sales of PCs and home appliances have added a large quantity of stock with respect to the use of electrical and electronic equipment.

Product lifetimes vary depending on the product category and market conditions for individual products. Theoretically, this lifetime can be modeled according to the products' accumulation distribution in the market (Wilkinson et al., 2001). However, such calculations require detailed market investigation and data, and the available

Table 1

Home appliances, PC sales and retention in China by 2003

\begin{tabular}{llll}
\hline Product & $\begin{array}{l}\text { Domestic sales } \\
\text { in 1990 (millions } \\
\text { of units) }\end{array}$ & $\begin{array}{l}\text { Domestic sales } \\
\text { in 2003 (millions } \\
\text { of units) }\end{array}$ & $\begin{array}{l}\text { Retention in } \\
\text { 2003 (millions } \\
\text { of units) }\end{array}$ \\
\hline TV sets & 6.74 & 42.29 & 420 \\
Refrigerators & 4.31 & 13.49 & 130 \\
Washing machines & 6.34 & 13.90 & 214 \\
Air conditioners & 0.24 & 11.80 & 60 \\
PCs & 0.03 & 9.60 & 39.8 \\
\hline
\end{tabular}

Source: National Bureau of Statistics (2004).

Notes: Domestic sales include both domestic production and importation. 
market data does not currently allow such calculations. In the study, the lifetime of home appliances is calculated based on official Chinese statistical data (Table 2).

With the rapid development of the IT industry, PC lifetimes are becoming shorter and shorter. Hence, one must assume a decreasing lifetime for PCs. Therefore, data on the lifetimes of selected electrical and electronic equipment was investigated with a questionnaire designed to determine the share of each product in the market in the given year. As a result, the distribution of PC lifetimes is shown in Fig. 1. The average PC lifetime for each year is calculated based on the distribution model (Table 3 ) and is given by:

Average life time (year) $=6^{*} S_{6}+5^{*} S_{5}+4^{*} S_{4}+3^{*} S_{3}$,

where $S_{i}(i=6,5,4,3)$ is the share of PCs whose lifetime is $i$.

Based on sales data statistics and the above lifetime distribution, the generation of WEEE quantities can be calcu-

Table 2

Lifetime of home appliances in China

\begin{tabular}{lc}
\hline Product & Lifetime (years) \\
\hline TV sets & 8 \\
Refrigerators & 9 \\
Washing machines & 9 \\
Air conditioners & 10 \\
\hline
\end{tabular}

Source:CRAES (2003).

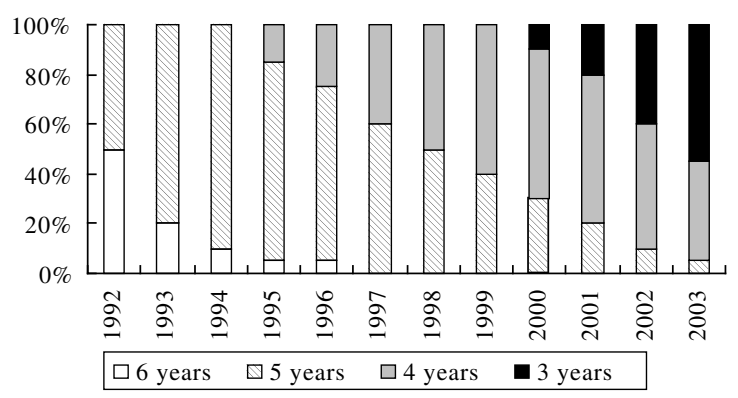

Fig. 1. Lifetime distribution for PCs in China.

Table 3

Average lifetime of PCs in China (\% of total PCs)

\begin{tabular}{llllll}
\hline Year & $\begin{array}{l}\text { Average } \\
\text { lifetime }\end{array}$ & $\begin{array}{l}\text { 6-year old } \\
(\%)\end{array}$ & $\begin{array}{l}\text { 5-year old } \\
(\%)\end{array}$ & $\begin{array}{l}\text { 4-year old } \\
(\%)\end{array}$ & $\begin{array}{l}\text { 3-year old } \\
(\%)\end{array}$ \\
\hline 1993 & 5.20 & 20.00 & 80.00 & & \\
1994 & 5.10 & 10.00 & 90.00 & & \\
1995 & 4.90 & 5.00 & 80.00 & 15.00 & \\
1996 & 4.80 & 5.00 & 70.00 & 25.00 & \\
1997 & 4.60 & & 60.00 & 40.00 & \\
1998 & 4.50 & & 50.00 & 50.00 & \\
1999 & 4.40 & & 40.00 & 60.00 & \\
2000 & 4.20 & & 30.00 & 60.00 & 10.00 \\
2001 & 4.00 & & 20.00 & 60.00 & 20.00 \\
2002 & 3.70 & & 10.00 & 50.00 & 40.00 \\
2003 & 3.50 & & 5.00 & 40.00 & 55.00 \\
\hline
\end{tabular}

Table 4

Estimate of obsolete WEEE in China (million tons)

\begin{tabular}{rrrrrl}
\hline Year & PCs & TVs & Refrigerators & Washing machines & Air conditioners \\
\hline 2003 & 4.48 & 33.51 & 9.76 & 7.56 & 0.65 \\
2004 & 7.31 & 28.81 & 9.75 & 9.50 & 1.43 \\
2005 & 9.81 & 32.32 & 13.57 & 15.22 & 1.62 \\
2006 & 10.73 & 40.88 & 11.12 & 8.00 & 2.81 \\
2007 & 12.68 & 44.49 & 11.38 & 10.83 & 3.23 \\
2008 & 15.13 & 44.60 & 10.79 & 10.98 & 4.01 \\
2009 & 15.57 & 48.43 & 12.32 & 13.40 & 4.76 \\
2010 & 19.57 & 55.73 & 11.87 & 12.61 & 5.50 \\
\hline
\end{tabular}

lated. As shown in Table 4, the calculated numbers of obsolete PCs, TV sets, refrigerators, washing machines, and air conditioners in 2003 were 4.48, 33.5, 9.76, 7.56 and 0.65 million units, respectively. In the future, the annual number of obsolete units of PCs and home appliances will increase due to both increasing sales numbers and the decreasing medium lifetime of these items.

In order to understand the total quantity of the material flows involved, the total mass balance was calculated assuming a specific medium weight. The results (Table 5) show that the total mass of obsolete WEEE (five categories) adds up to 1.76 million tons in 2003, where TV sets are the dominant contributor and account for $47.7 \%$ of the total mass.

In addition to the rapid growth of domestic WEEE, imported WEEE from other countries will put even more pressure on Chinese waste management. Currently, it is not clear how much WEEE is imported from other countries. According to an environmental group's estimations (Basel Action Network, 2002), 20 million PCs became e-waste in the United States in 1998, which accounts for a WEEE quantity of 5-7 million tons. According to the authors, an estimated $50-80 \%$ of WEEE collected in the United States was exported to China and other Asian countries.

According to Chinese regulations, the import of waste batteries and 21 kinds of electrical and electronic appliances was prohibited as of August 15th 2002. This prohibited list includes not only the products but also the parts, including dismantled and crushed parts. However, waste electric motors, electrical scraps, waste wires and cables can be imported because they can be used as raw materials. Subsequently, their import was only restricted and not banned by the Chinese government.

In the importation business, it is not easy to distinguish between legal and illegal importation. Illegal importation of WEEE from other countries exists, but there is no statistical data for the quantity of illegal imports of WEEE into China. According to reports on WEEE treatment in Guiyu, Shantou, about $30,000-40,000$ people are involved in WEEE treatment, treating over 1 million tons of WEEE annually (Xinhua News, 2005). Illegally imported WEEE is treated with crude recycling methods, which have caused serious air, water and soil pollution, as well as damage to human health (Wong, 2005). 
Table 5

Total WEEE weight estimation in 2003

\begin{tabular}{|c|c|c|c|c|c|c|}
\hline & $\mathrm{PCs}$ & TV sets & Refrigerators & Washing machines & Air conditioners & Total weight (million tons) \\
\hline No. of units (million) & 4.48 & 33.51 & 9.76 & 7.56 & 0.65 & \\
\hline Unit weight (kg/unit) & 27 & 25 & 59 & 25 & 51 & \\
\hline Weight (million tons) & 0.12 & 0.84 & 0.58 & 0.19 & 0.33 & 1.76 \\
\hline
\end{tabular}

\subsection{WEEE flow in China}

Chinese domestic WEEE flows are far from understood. Most WEEE recycling activities are spontaneous. The existing WEEE flow system, shown in Fig. 2, depicts the understanding of the current situation drawn from an investigation in Beijing. According to this flowchart, $70 \%$ of end-of-life e-products are stored in homes or offices. The storage time varies from several months to several years. Key factors that determine storage time are the collection system and collection costs.

The system chart also shows that only about $12 \%$ of WEEE is disassembled or dismantled for material recovery collection by peddlers; only this small part of the WEEE flow will be sorted and treated for reuse or recovery of base materials. The majority of IT equipment and devices, such as PCs and mobile phones, are often technically in working order even if they do not utilize the latest technical standards. After repairing, upgrading or refurbishing, these obsolete products are still functional for some time. Normally, these second hand products are used in rural areas or poorer regions. At the end-of-life of these second hand products, they will then enter the WEEE flow. However, the lifetime of second hand products has not been investigated scientifically.

WEEE entering the material recovery process is disassembled, dismantled and treated by hand. The advantage of this manual treatment is that some usable parts or components will be sorted and reused in the market as second hand components. Currently, reuse creates much more profit than material recovery because the second hand market pays much higher prices for reusable components or items than the final material value of the products. Some-

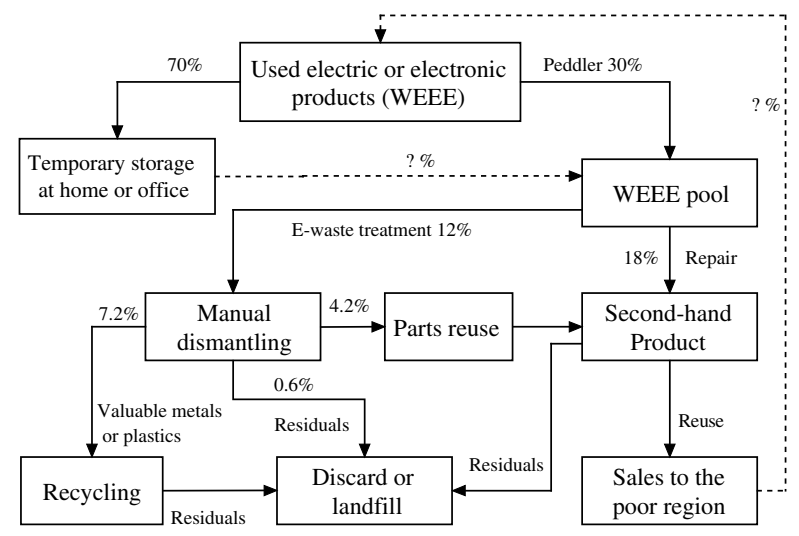

Fig. 2. WEEE Flow in China. times, the used product is sold as new after a simple repair or esthetical refurbishing. Second hand products are not certified or tested by an independent organization. If and when such an organization will come into being is an open question.

Simply put, WEEE recycling offers great potential. More attention should be paid to both material recovery and the reuse of whole appliances and components.

\section{Chinese WEEE recycling system}

\subsection{The situation of WEEE recycling in China}

Due to the lack of legislation in China, reuse and recycling often occur informally. An authorized testing and certification organization for second hand products does not exist. Consequently, the reuse of products is uncontrolled (e.g., some used products are sold as new after simple repair). Some refurbished products with reused components have caused serious security problems (e.g., exploding used-CRT television tubes) (China Times News, 2007). In general, the dishonest portion of the second hand market can make higher profits than the normal market.

Currently, WEEE recycling activities can be distinguished between domestic WEEE recycling and mixed metals recycling from imports. By 2005, 503 authorized recyclers for imported waste materials had been registered and are mainly located in the eastern coastal area. These businesses might be potential recyclers for domestic WEEE in the future. In some regions, like Guiyu or Taizhou, illegal WEEE recycling has caused severe environmental pollution.

For domestic WEEE recycling, no authorized recyclers have yet been identified, with the exception of four national pilot projects. Recently, several industrial companies have also set up WEEE recycling facilities. The Dowa Company, for example, has set up one recycling factory in Suzhou city specifically for printed circuit boards. Until now, the Dowa factory has only treated WEEE production waste from industrial processes. However, the volume of WEEE from industries is not enough to make Dowa's recycling profitable. In the future, post-consumer WEEE will also be recycled in Dowa's facilities.

\subsection{Environmental problems from WEEE recycling}

According to an investigation and analysis of WEEE flows in Taizhou, Zhejiang Province, the main environmental problems from WEEE recycling are energy consump- 
tion and secondary pollution. In general, disassembly and dismantling are done by hand or using very simple tools. Pollution occurs when crude methods are applied, such as open burning of wire and cable, open melting of a motor's rotor to extract aluminum and copper, as well as disassembling transformers without preventing oil from leaching into the water and soil. Open melting of aluminum and copper from disassembled WEEE to cast it into ingots causes air pollution and damages the health of workers. In general, illegal treatment of imported WEEE by burning or extracting metals in acid baths is toxic to workers directly and results in serious water and air pollution in the local vicinity.

More attention must be paid to the treatment of residues from the recycling process, which are presently sent directly to a landfill site for municipal waste or dumped elsewhere. Heavy metals, like $\mathrm{Pb}, \mathrm{Hg}$, and $\mathrm{Cr}$, among others, are leaching into the groundwater, which may lead to toxic impacts on the local environment in the long term. Air pollution and leaching liquids from landfill sites have also threatened public health and the local environment.

\subsection{National pilot projects for domestic WEEE management}

Industries and the Chinese government lack information to create policies and regulations due to the informal nature of existing WEEE recycling activities, which naturally do not collect or provide detailed information. Therefore, four national pilot projects for WEEE recycling and management have been launched since 2004. The objectives of the pilot projects can be summarized as follows:

- To set up and support WEEE management institutions and policies.

- To set up a collection network for domestic WEEE.

- To help develop standards and regulations for WEEE management.

- To develop key technologies and equipment for WEEE recycling.

According to the above objectives, specific task forces were set up at both the city and province level.

One pilot project is located in Tsingdao city in Shandong Province; it is the only project on the city level. The project's goal is to set up a collection network and further develop recycling technologies. The Haier Recycling Center is under construction and expected to be finished in 2007. In phase I of the plan, 200,000 used home appliances, including TV sets, air conditioners and washing machines, will be recycled per year. The final recycling capacity will be up to 600,000 appliances per year. This recycling center will run in combination with the Tsingdao city hazardous waste treatment center (Fig. 3).

As far as the collection network is concerned, very slow progress has been made. The key obstacle for setting up a network is the collection cost. In 2004, Tsingdao city discarded 250,000 TV sets, 100,000 refrigerators, 100,000

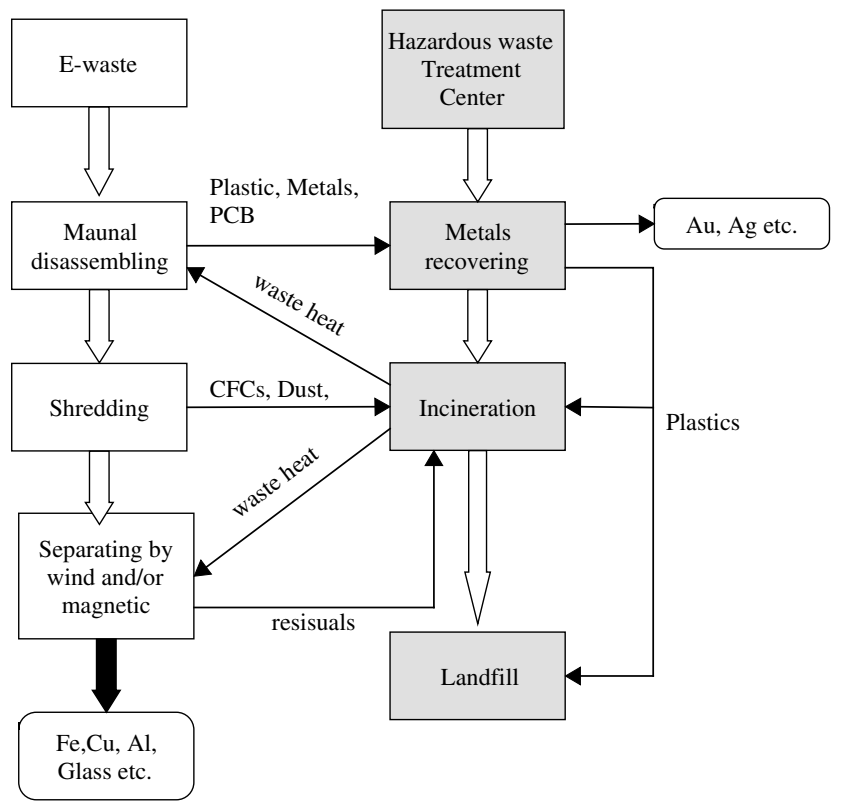

Fig. 3. Flowchart for the Haier recycling center.

washing machines and 150,000 PCs. However, the pilot project recycling center, with a capacity of 200,000 items, collected less than 1000 home appliances.

A second pilot project for WEEE recycling is based in Zhejiang Province and represents a demonstration program at the provincial level. Its aim is to:

- Develop disassembling/dismounting techniques and the necessary equipment to perform the work.

- Construct the Zhejiang Recycling Center to recycle TVs, refrigerators and printed circuit boards (with a total the capacity of 15 tons of home appliances).

- Explore WEEE collection patterns.

Zhejiang Recycling Center is currently under construction, as is the relevant recycling technology and equipment. During the set up of the collection system, two types of collection models were developed. One type is an exchange model, under which end-of-life products can be replaced with new appliances at a shopping center. The other model focuses on setting up curbside collection in individual communities. Additionally, other collection types will be tested, such as door-to-door collection, manufacturing-site collection and collection at governmental institutions.

Two additional pilot projects are located in Beijing and Tianjin, respectively, but they are still in the planning phase.

\subsection{The situation of recycling imported WEEE}

According to Chinese laws and regulations, most WEEE is forbidden to be imported. The list of forbidden WEEE import products can be seen in Table 6. It is clear that most end-of-life home appliances and IT products are prohibited from being imported into China. Exceptions are cables, 
Table 6

List of forbidden WEEE imports

\begin{tabular}{lll}
\hline No. & Product code & Product name \\
\hline 01 & $8415.1010-8415.9090$ & Air conditioners \\
02 & 8417.8020 & Furnaces for radioactive waste \\
03 & $8418.1010-8418.9999$ & Refrigerators, freezers, etc. \\
04 & $8471.1000-8471.5090$ & Computers \\
05 & 8471.6010 & Monitors \\
06 & $8471.6031-8471.6039$ & Printers \\
07 & $8471.6040-8471.9000$ & Computers peripheral equipment \\
08 & 8516.5000 & Microwave ovens \\
09 & 8516.6030 & Electric pots and cookers \\
10 & $8517.1100-8517.1990$ & Telephone sets and videophones \\
11 & $8517.2100-8517.2200$ & Fax machines and teleprinters \\
12 & $8521.1011-8521.9090$ & Video recorders and laser disk players \\
13 & $8525.2022-8525.2029$ & Mobile communication equipment \\
14 & $8525.3010-8525.4050$. & Video cameras and digital cameras \\
15 & $8528.1210-8528.3020$ & TV sets \\
16 & $8534.0010-8534.0090$ & Printing circuit boards \\
17 & $8540.1100-8540.9990$ & Thermionic, cold CRT and photo- \\
8 & $8542.1000-8542.9000$ & cathode tubes \\
19 & $9009.1110-9009.9990$ & Pomponents of ICs or molectrons \\
20 & $9018.1100-9018.9090$ & Instruments and appliances used in \\
& & medical science \\
21 & $9022.1200-9022.9090$ & Apparatus based on X-rays \\
\hline
\end{tabular}

wires, mixed metals, motors and other components if they can be used as raw materials. These materials can be imported and recycled by authorized recyclers.

In 2005, there were a total of 503 recyclers who imported and recycled 9.55 million tons of mixed metals, cables, motors and other pre-processed products. These recyclers are mainly located in the eastern coastal area and together form three regional recycling centers. In the Tianjin area, recycling mainly consists of cables and mixed metals. The Zhejiang area mainly recycles motors and mixed metals. Guangdong mainly deals with mixed home appliances and printed circuit boards.

These recyclers have experience disassembling and dismantling WEEE and also have established a good network for recovered materials. In the future, these companies might be candidates for becoming authorized recyclers for domestic WEEE.

\subsection{Cost analysis of WEEE recycling}

Based on information gained from the national pilot projects and through observing informal recyclers, collection plays a very important role in the recycling process. A reliable, safe and efficient collection system will motivate recycling activities and reduce costs. In general, the existing informal collection network is much more efficient than the formal collection system applied in the national pilot projects. Table 7 lists the cost breakdown per unit for informal and formal recycling activities. Information on payments made to owners and on transport costs were acquired from our investigation from Beijing. The value after recycling is the sum of the value (market material price) of materials recovered.
Table 7

Cost analysis for WEEE collection and recycling (RMB)

\begin{tabular}{lllll}
\hline $\begin{array}{l}\text { Home } \\
\text { appliances }\end{array}$ & $\begin{array}{l}\text { Payment to } \\
\text { owner }\end{array}$ & $\begin{array}{l}\text { Transport } \\
\text { cost }\end{array}$ & $\begin{array}{l}\text { Value after } \\
\text { recycling }\end{array}$ & Benefit \\
\hline $\begin{array}{l}\text { For informal recyclers } \\
\text { TV sets }\end{array}$ & 80 & & & \\
Refrigerators & 120 & 5.0 & 150 & 65.0 \\
$\begin{array}{l}\text { Air conditioners } \\
\text { Washing }\end{array}$ & 120 & 10.0 & 200 & 70.0 \\
$\quad 60$ & 10.0 & 200 & 70.0 \\
$\quad$ machines & 120 & 10.0 & 120 & 50.0 \\
$\begin{array}{l}\text { PCs } \\
\text { For pilot project recyclers }\end{array}$ & 5.0 & 150 & 25.0 \\
TV sets & 156 & 14.5 & 20 & \\
$\begin{array}{l}\text { Refrigerators } \\
\text { Air conditioners }\end{array}$ & 165 & 308 & 172 & -150.5 \\
Washing & 115 & 30.8 & 100 & -238.7 \\
$\quad$ machines & 150 & 19.3 & 40 & -94.3 \\
PCs & & & & 2.7 \\
\hline
\end{tabular}

Table 7 shows that informal recyclers make a good profit from recycling, while the formal (pilot project) recyclers suffered a deficit in the recycling of many appliances. It is noticeable that payments to owners account for a sizable contribution to the total cost balance. Informal recyclers get WEEE at lower costs than formal collectors. Formal recyclers also have to pay more if they buy the material from informal collectors. Informal recyclers have lower labor and operating costs than formal ones because they usually transport WEEE by tricycle instead of truck.

The above cost analysis explains why the national pilot programs have not succeeded in collecting larger quantities of WEEE. Under the existing policy framework, formal recyclers will not be successful while competing against informal recyclers unless they become more cost efficient. Therefore, policies and regulations for WEEE management have to be updated and improved.

\section{WEEE management regulation trends in China}

\subsection{Policy framework for WEEE management in China}

Chinese policies and regulations for controlling environmental problems that result from current WEEE management are presently being drafted. Currently, there are three government agencies working on regulating WEEE management. The National Development and Reform Commission (NDRC) finished work on a policy entitled, "Management of Recycling Home Appliances and Electronic Equipment," in November 2004, constructed for the purpose of increasing resource efficiency (presently being publically reviewed). The State Environmental Protection Administration (SEPA) issued a separate paper, "Document on environmental management of WEEE," in 2003, which generally outlines WEEE issues and related policy trends. SEPA is also drafting a "Technical policy of WEEE pollution prevention and control," which aims to 
minimize pollution from end-of-life treatments. Finally, SEPA issued the "Regulating the list of forbidden import goods," which includes 21 categories of WEEE. The third organization dealing with WEEE issues is the Ministry of Information Industry (MII). This ministry issued a brief titled, "Pollution control and management of IT products" on February 28, 2006, due to be enforced 1 March 2007; it aims to prevent pollution from the source. Fig. 4 lists the involved organizations and relevant legal documents.

\subsection{Focus points of policies and regulations}

The focus of the NDRC's policy can be summarized in several main points.

(1) The WEEE categories that should be managed first are TVs, refrigerators, washing machines, air conditioners and personal computers. In the future, this list will be changed according to the situation.

(2) Multiple open collection systems should be established. Collection can be done by any interested parties with the condition that they transfer the collected WEEE to authorized recyclers (licensed or certificated).

(3) A recycler certification system should be launched. Any party, whether a producer or other industrial company, can set up a recycling and disposal system but must undergo a certification process.

(4) The responsibilities of interested parties are defined as follows: (a) distributors have responsibility for WEEE collection and delivery of WEEE to recyclers; (b) recyclers are responsible for reuse, disassembly, and final deposition; and (c) consumers have to collect and hand over their own WEEE to certified collectors.

(5) A special National Fund, which is funded by producers and other sources will be founded to promote the above-mentioned activities for WEEE recycling.
MII's policies focus on IT products and their associated environmental issues. The guidelines have been inspired by the EU's directives on WEEE and RoHs. The key policy elements are summarized according to the following principles.

(1) Design and production, as well as the packaging of IT products, need to be done in an environmentally sound way with prior thought given to recycling issues.

(2) Materials containing $\mathrm{Pb}, \mathrm{Hg}, \mathrm{Cd}, \mathrm{Cr}^{6+}, \mathrm{PBB}$ or PBDE will be forbidden in the production of electrical and electronic equipments. No deadline has been fixed yet.

(3) IT products for sale must label toxic and harmful materials contained in the product, the period of safe use and the potential for recycling.

(4) Producers (including importers) of IT products are responsible for collecting, recycling, and disposing of their products at the end-of-life.

The "Technical policy of WEEE pollution prevention and control" that was prepared by SEPA mainly focuses on the end-of-life of products; it integrates the $3 R$ (Reduce/Reuse/Recycling) principles and takes the whole life cycle perspective into account. The key points of the SEPA policy are relayed by the following points.

(1) Design products with the environment in mind to prohibit the use of toxic substances, prolong the lifetime of products and enable easy recycling.

(2) The product information disclosure should include information about any toxic substances contained in the product, reusable and recyclable parts and final disposal.

(3) A reuse assurance system should be created to provide technical check ups, classification, labeling, marking and quality assurance of reused components.

Law of solid waste pollution prevention and control Law of clean production promotion

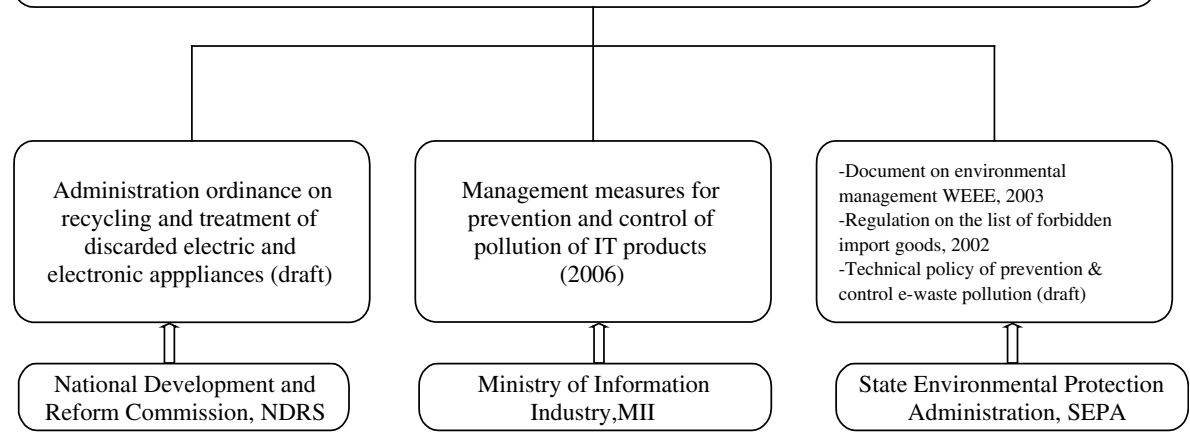

Fig. 4. Structure of organization and policy for WEEE management. 
(4) An environmentally sound dismantling process must be created for hazardous substances and parts, such as CRTs, LCDs, gas discharge lamps (which contain mercury), printed circuit boards, PCB-containing capacitors, mercury-containing components (such as lamps and switches) and batteries. The plastic containing brominated flame retardants should also be dealt with safely.

The most important policy trend is outlined in the NDRC's regulation. All WEEE regulations should be in accordance with NDRC's policy. NDRC has not yet clearly defined the producer's responsibilities. Discussion among government agencies is still ongoing.

The implementation of e-waste regulations will be carried out by local governments instead of the central administration. Local governments will draft a detailed action plan to implement national regulations and laws according to their local conditions. Supervision and amendment of the action plan will be also carried out by local governments.

As a whole, China will be faced with an increasing WEEE volume, which has to be managed appropriately. The recycling policy and related regulations need to be based on extended producer responsibility principles. Small sized recycling companies have to be developed either into larger businesses with newer, more advanced technology and more efficient facilities or forbidden at all. Much attention should be given to recycling control and pollution prevention. Policies should facilitate environmentally sound management of WEEE by supporting a cooperative network between recycling companies and manufacturers.

\section{Conclusion and suggestions}

With domestic WEEE generation expanding, the pressure for environmentally friendly recycling of both domestic and imported WEEE is reflected in the government's policy agenda. Analysis of WEEE flows shows that a large quantity of e-waste will be generated in the near future. Existing recycling capacity will not be able to deal with the requirement of environmentally friendly recycling. In order to support WEEE legislation and related policy development, a detailed MFA or LCA study on WEEE flow in China is urgently required on the agenda of waste researchers.

China cannot fully duplicate the EU or USA models for WEEE management. However, the recycling technology and experiences of advanced countries can be used in China, but a special system should be established according to Chinese WEEE flow and recycling practices. The main challenge is how to transform or integrate existing informal recyclers into the formal recycling sector.

Informal WEEE recycling is currently the dominant practice. The effect on the environment is becoming serious. The establishment of an effective collection network is the key factor for the development of an environmentally sound recycling industry of WEEE in China. Furthermore, recycling costs, especially collection costs, affect e-waste flows and determine the success or failure of the national pilot projects. If the existing capacities of the informal sector can be certified and controlled, they could play an important role in recycling domestic WEEE. Integrating small-sized, scattered, informal recyclers will achieve both economic and ecological benefits.

It is strongly suggested that policies and regulations associated with WEEE management should be drafted and issued urgently. The extended producer responsibility mechanism should be clearly defined. Advanced recycling technology should be adapted to the Chinese local situation and management. Much attention should also be paid to pollution prevention and recycling control of WEEE. It is imperative to set up a cooperative network between recycling companies and manufacturers.

\section{Acknowledgements}

Funding for this study was provided by the "National Basic Research (973) Program" Project (No. 2005CB 724206) of the Ministry of Science and Technology of China. Great thanks is extended to Dr. Martin Streicher-Porte for his help in language editing.

\section{References}

The Basel Action Network (BAN), Silicon Valley Toxicity (SVTC), 2002. Exporting harms, <http://www.svtc.org/cleancc/pubs/technotrash. pdf>.

China Times News, 2007. <http://www.chinatimes.cc/shendu/hxsd/200702-05/20070205233542.html>.

CRAES (Chinese Research Academy for Environmental Science), 2003. Electric and Electronic Waste Control (internal report in Chinese). EEA. 2003. Waste from electrical and electronic equipment (WEEE). European Environment Agency, Copenhagen.

EU, 2002. Directive 2002/96/EC of the European Parliament and of the Council of 27 January 2003 on waste electrical and electronic equipment (WEEE).

Huisman, J., 2003. The QWERTY/EE Concept, Quantifying Recycability and Eco-efficiency for End-of-life Treatment of Consumer Electronic Products. Delft University of Technology, Delft.

Li, J., Wen, X., Liu, T., Honda, S., 2004. Policies, management, technologies and facilities for the treatment of electronic and electric wastes in China, In: Proceedings of China-Netherlands Seminar on Recycling of Electronics in Beijing, China on November 16-17, 2004.

Lin, F., Wang, Y., 2003. Generation estimation of obsolete PCs in China. Shang Environmental Sciences (7), 479-494 (in Chinese).

Liu, X., Yang, J., 2005. Estimation of WEEE generation in China, China population. Resources and Environment 15 (5), 113-117, in Chinese.

Matthews, H. S., Matthews, H.D., 2003. Information technology products and the environment. In: R. Kuehr, E. Williams (Eds.), Computers and the Environment: Understanding and Managing their Impacts. Kluwer Academic Publishers/Springer, Dordrecht, The Netherlands, pp. 1739

Matthews, H.S., McMichael, F.C., Hendrickson, C.T., Hart, D.J., 1997. Disposition and end-of-life options for personal computers. In: Green Design Initiative Technical Report No.97-10.Carnegie Mellon University.

Ministry of Information Industry, 2004. Pollution control and management of IT products (internal report).

Ministry of Information Industry, 2006. Management measures for prevention and control of pollution of IT products. 
National Bureau of Statistics of China, 2004. Statistic Year Book, 2004. NDRC, 2004. "Management of Recycling of Home Appliance and Electronic Equipment", (public review version).

Renningen, B., 2005. Competitors together in PRO (Producers Responsibility Organisation) - a case study of the PRO-system in Norway. In: Proceedings of the 2005 IEEE International Symposium on Electronics and the Environment. pp. 45-48.

SEPA, 2004, Technical policy of WEEE pollution prevention and control. Streicher-Porte, M., 2005, WEEE recycling systems: the Swiss solution SEICO. In: Proceedings of the Second NIES Workshop on E-waste, Tsukuba, Japan.

Wang, S., Li, G., Liu, Z., Song, S., 2006. Study on the reutilization technology of waste household appliances. Technology on Home Appliances 3, 70-74 (in Chinese).
Wilkinson, S. et al., 2001. Waste from electrical and electronic equipment in Ireland: a Status Report. Environmental Protection Agency in Ireland.

Williams, E., Sasaki, Y., 2003. Strategizing the end-of-life handling of personal computers: resell, upgrade, recycle. In: Kuehr, R., Williams, E. (Eds.), Computers and the Environment: Understanding and Managing their Impacts. Kluwer Academic Publishers, Dordrecht, The Netherlands, pp. 183-196.

Wong, M.H., 2005. Environmental and health effects of electronic waste recycling. In: Proceedings of Second NIES Workshop on WEEE, November 23, 2005, Tokyo.

Xinhua News, 2005. <http://news.xinhuanet.com/fortune/2005-09/03/content_3437772.htm> (in Chinese). 